\title{
Recent Advances in Mitigation of Whiskers from Electroplated Tin
}

\author{
B.S. MAJUMDAR @if, ${ }^{1,5}$ I. DUTTA, ${ }^{2,6}$ S. BHASSYVASANTHA, ${ }^{1,3}$ and \\ S. DAS MAHAPATRA ${ }^{2,4}$ \\ 1.-Materials and Metallurgical Department, New Mexico Tech, Socorro, NM 87801, USA. \\ 2.-School of Mechanical and Materials Engineering, Washington State University, Pullman, \\ WA 99164, USA. 3.-Present address: Molex LLC, 2025 Taylor Road, Auburn Hills, MI 48326, \\ USA. 4.-Present address: Intel Corporation, Materials Technology Development, ATTD, Cha- \\ ndler, AZ 85226, USA. 5.—e-mail: bhaskar.majumdar@nmt.edu.6.—e-mail: idutta@wsu.edu
}

Tin whiskers pose an electrical reliability risk in the form of potential short circuits. This problem was solved in the past by adding a few percent of $\mathrm{Pb}$ during Sn electroplating, but with the ban on $\mathrm{Pb}$ in Europe and elsewhere, it has resurfaced. While various mitigation strategies have been formulated based on known whisker growth mechanisms, the electronic industry is still awaiting a satisfactory solution to the whisker growth problem in $\mathrm{Pb}$-free electronics. Recent advances in the understanding and mitigation of whiskers are reviewed herein. The effects of various alloying elements/dopants are discussed in terms of the mechanisms that impact whisker growth kinetics and mitigation. Most recently, indium addition to $\mathrm{Sn}$ has been found to eliminate whiskers with even better mitigation performance than $\mathrm{Pb}$ addition. The mechanisms are discussed, and the important role of indium on the surface oxide and subsurface enrichment is highlighted.

\section{INTRODUCTION}

In electronic packages, copper lead-frames are usually plated with $5-\mu \mathrm{m}$ - to $20-\mu \mathrm{m}$-thick $\mathrm{Sn}$ or Snrich alloy (e.g., eutectic $\mathrm{Sn}-\mathrm{Cu}$ ) to serve as a wetting enhancer during subsequent soldering for lead attachment, and to reduce oxidation and corrosion of the lead-frame. Frequently, Sn whiskers, which may be hundreds of micrometers long, extrude from the electroplated surface during long-term isothermal holding or thermal cycling, potentially causing electrical shorts between neighboring circuitry. Failures due to short-circuiting caused by whisker growth or debris have been reported in high-power devices in civil, military, and space avionics, as well as in consumer electronics. ${ }^{1,2}$

\section{WHY DO WHISKERS GROW?}

Whiskers have been observed in various systems (including $\mathrm{Sn}$ on $\mathrm{Cu}, \mathrm{Al}$ on $\mathrm{Si}$, and $\mathrm{Zn}$ on steel) since the 1950s. ${ }^{3-21}$ Figure 1a shows a focused ion beam (FIB) cross section of a $\mathrm{Sn}-2 \mathrm{Cu}$ electroplated film, illustrating one such whisker emanating from the film following aging at room temperature (RT). ${ }^{14} \mathrm{~A}$ number of reasons for whisker formation have been suggested, but there is now a general consensus that three key conditions have to be satisfied for whisker growth, ${ }^{14,22-24}$ viz. (1) a mechanism to generate in-plane compressive stresses within the coating to provide the driving force for whisker growth, (2) rapid grain boundary self-diffusion to transport matter from the plating interior to the growing whisker, and (3) a tenacious surface oxide layer which limits surface vacancy sources, thereby precluding stress relief via diffusional processes. While there has been some controversy regarding the oxide scale based on high-vacuum work such as that presented in Ref. 25, the need for a tenacious oxide layer is largely well established.,26

The principal driving force for whisker growth in metal films is generally thought to be stressassisted diffusion of atoms from the film/plating interior to the surface (or conversely, vacancy diffusion from the film surface to the film interior). This diffusion occurs to relieve the in-plane compressive stresses, whose origin can be traced to a variety of sources: (i) spontaneous reaction between the substrate and film to form an intermetallic 


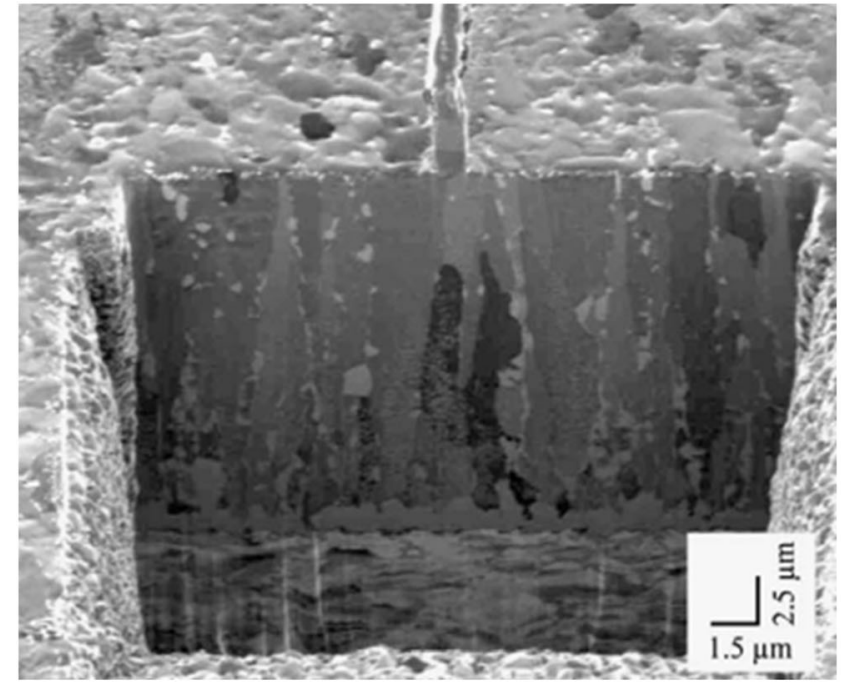

(a)

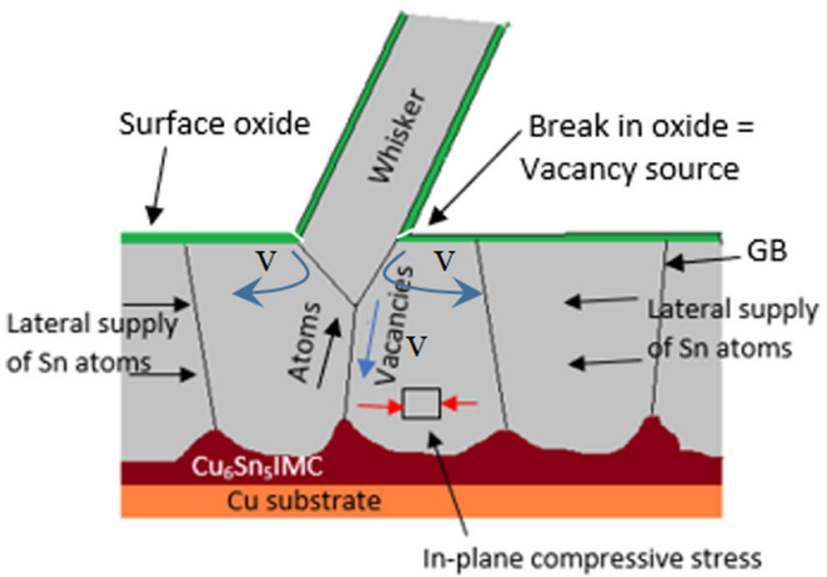

(b)

Fig. 1. (a) FIB-milled cross section at location of Sn whisker in 16- $\mu$ m-thick $\mathrm{Sn}-2 \mathrm{Cu}$ electroplating on bronze substrate, showing tall columnar grains and interfacial reaction zone; reprinted with permission from Elsevier. ${ }^{14}$ (b) Schematic showing mechanism of whisker growth with vacancy flux directions marked as "v," along with concomittent diffusion of Sn atoms to the whisker base.

compound (IMC) layer in the form of $\mathrm{Cu}_{6} \mathrm{Sn}_{5}$, as pointed out in the now classical paper by $\mathrm{Tu}^{22}$ for $\mathrm{Sn}$ on $\mathrm{Cu}$ (the same being true for $\mathrm{Al}$ on $\mathrm{Si}$ ), (ii) thermal stresses generated through thermal cycling and brought about by thermal expansion mismatch between the film and substrate ${ }^{27,28}$ or (iii) imposed compressive mechanical stress, as occurs in electronic connectors. ${ }^{29}$ While some dislocation-based stress relaxation processes may occur, the stress must be long lasting given the growth of whiskers over long time periods. $\mathrm{Tu}^{22,30}$ correctly pointed out that compressive stress could be maintained by the spontaneous reaction between $\mathrm{Sn}$ and $\mathrm{Cu}$ at $\mathrm{RT}$ because of the high diffusivity of $\mathrm{Cu}$ into $\mathrm{Sn}$ through the $\mathrm{Cu}_{6} \mathrm{Sn}_{5}$ layer. Normally, excess diffusion of one element into another does not lead to stress development, and so it follows that there is an additional factor that is responsible for maintaining the stress through a reaction product. Lee et al. ${ }^{31}$ argued that the greater IMC formation at Sn grain boundary/substrate interfaces compared with other regions of the $\mathrm{Sn} / \mathrm{Cu}$-substrate interface was responsible for the compressive stress development, and this has been found to be consistent with most experimental observations. It also follows that, if the reaction zone could be held planar, then the compressive stress and particularly the horizontal hydrostatic stress gradient would be reduced, thereby reducing whisker formation and growth. A number of papers have suggested that this mechanism does indeed operate for $\mathrm{Sn}-\mathrm{Pb}$ and $\mathrm{Sn}-\mathrm{Bi}$ films. ${ }^{32,33}$ For example, atomic force microscopy (AFM) scans of the IMC-covered surface after the $\mathrm{Sn}-\mathrm{Pb}$ film was stripped from the substrate showed a more homogeneous $\mathrm{Cu}_{6} \mathrm{Sn}_{5}$ distribution. The IMCs were much smaller than for the pure Sn film, although the total IMC content was not reduced while Sn was substituted by $\mathrm{Pb}^{32}$ A similar change in IMC morphology was observed for Sn-Bi alloys ${ }^{33}$ with sharply reduced whisker growth. However, it remains to be determined how dominant this mechanism is compared with other mechanisms such as the equiaxed form of the microstructure or the mobility of grain boundaries, both of which may contribute to stress reduction.

Returning to the subject of whisker growth by diffusion, the plating surface needs to be a prolific source of vacancies, which is not possible if the surface oxide film is stable and adheres tenaciously to the plating surface. This is the situation with $\mathrm{Al}^{34-36}$ and Sn films. However, local breaks in the surface oxide can provide localized stress relief, resulting in a stress gradient either from the high compressive stress location around the wedgeshaped IMCs or from lateral locations in the film where the surface oxide is intact, to near-zero stress at the oxide break. Both of these stress gradients have been confirmed by high-energy x-ray synchrotron studies $^{24,37,38}$ for the $\mathrm{Sn}-\mathrm{Cu}$ system. The associated vacancy flux counter to the stress gradient, indicated by the letter "v" in Fig. 1b adapted from Refs. 24 and 39, is accompanied by an Sn atom flux counter to the vacancy flux, and this results in growth of the whisker. The vertical grain boundaries of the columnar grains in typical platings constitute the principal diffusion path, the kinetics of whisker growth being governed by grain boundary diffusion kinetics. ${ }^{22,24}$ In the model, it is shown that the whisker growth rate is linearly proportional to the Sn diffusivity and compressive stress in the film, although it must be remembered that diffusion occurs because of the stress gradient, and not the value of compressive stress. 
In recent work, Chason et al. ${ }^{26,40,41}$ studied the dependence of the whisker/hillock nucleation rate on stress in a ( $\mathrm{Sn}$ on $\mathrm{Si}$ ) system without intermetallics, where the stress is entirely thermally generated, revealing that increasing stress increases the nucleation rate, which stops when the stress relaxes to a threshold level. They showed that the stress relaxes more rapidly for thicker Sn coatings, and expectedly the volume of whiskers nucleated decreases. Their work also shows that stresses are lower in coarser matte-Sn grains compared with finer grains with bright-Sn finish. Using FIB cross sections, Pei et al. ${ }^{42}$ observed oblique grain boundaries just below a whiskering grain/grains (see the oblique V-shaped grain boundaries in the sketch of Fig. 1b). This was also observed by Sarobol et al. ${ }^{43}$, and a whisker growth model ${ }^{44}$ was proposed using the $\mathrm{V}$-shaped boundary near the surface and combining the effects of local grain boundary sliding and diffusional transport of atoms from the horizontal components of the oblique boundaries. More importantly, by including the observed effect of lateral grain boundary migration, the model could also account for the presence of hillocks rather than whiskers.

Some studies have suggested that a surface oxide film is not necessarily critical for whisker growth. ${ }^{11,25}$ However, it has been shown ${ }^{26}$ that removal of the surface oxide dramatically reduces the compressive stress within the coating, thus reducing the driving force for whisker growth. One of the early works demonstrating the need for a protective oxide layer for whisker formation was that of Chang and $\mathrm{Vook}^{45}$ for the Al-Si system in high- and ultrahigh-vacuum (UHV) environments. They demonstrated that, in the absence of a surface oxide in UHV, no hillock formation occurred in vapor-deposited aluminum films on silicon substrate. It was suggested that the compressive stress was greatly relieved in the presence of the oxidefree surface. In a slightly related work for the $\mathrm{Sn}-\mathrm{Cu}$ system, ${ }^{46}$ the compressive stress was found to relax in the electrolyte when electrodeposition of Sn was temporarily stopped, since oxides were unlikely in the electrolyte. The need for an adherent oxide scale was also demonstrated in the case of thin $\mathrm{Ag}$ film coated with a few-nanometer-thick adherent $\mathrm{SnO}_{2}$ layer, where whiskers were found to emanate from the Ag film. ${ }^{47}$ Ashworth et al. ${ }^{48}$ showed that Sn deposited on brass then treated by electrochemical oxidation of the surface layer was significantly less susceptible to whisker growth than the native oxide film. It was argued that the electrochemically deposited oxide film was thicker and therefore less prone to fracture than naturally grown oxide film. Other observations that illustrate the role of the oxide in whisker growth include the often-observed striations on tin whiskers, which are believed to result from intermittent growth and breakage of the natural oxide film.
Boettinger et al. ${ }^{14}$ investigated the role of the microstructure in whisker growth. In $16-\mu \mathrm{m}$-thick $\mathrm{Sn}$ and $\mathrm{Sn}-\mathrm{Cu}$ films, the grains were columnar and profuse whiskering was observed in the $\mathrm{Sn}-\mathrm{Cu}$ sample, suggesting that columnar grains are prone to whisker growth (Fig. 1a). In contrast, an equiaxed microstructure with oblique and horizontal grain boundaries was found in $\mathrm{Sn}-2 \mathrm{~Pb}$ alloys, and hillocks of only a few microns height were observed. The microstructure illustrated in Fig. 2a is taken from their work. This is also consistent with the much weaker fiber texture found in $\mathrm{Pb}$ containing Sn deposits. ${ }^{49}$

Galvanostatic studies indicate that $\mathrm{Pb}$ additions to the electrolyte tend to lower the electrode potential, suggesting inhibition of Sn ion reduction at the cathode in favor of $\mathrm{Pb}$ ion reduction. It is suggested that this suppression of $\mathrm{Sn}^{2+}$ reduction during the codeposition process likely prevents continued columnar growth, and thereby a transition to a more equiaxed microstructure for the $\mathrm{Sn}-\mathrm{Pb}$ system. ${ }^{50}$ The primary importance of the many grain boundaries (GBs) parallel to the plating surface is that they produce numerous vacancy sources within the film. As shown schematically in Fig. 2b, the grain interiors and the vertical grain boundaries are in in-plane compression. This drives a vacancy flux from the horizontal boundaries towards the bottom of the plating, where the compressive stresses are maximum, ${ }^{19,22,23}$ with a counterflux of atoms flowing to the horizontal boundaries, which can serve as atom sinks. As a result, the atoms do not need to reach the plating surface to relieve the stress by extrusion of whiskers. This architecture, with a number of horizontal boundaries or interfaces within the plating, thus proffers a potential mechanism for whisker mitigation. A number of publications since then have appeared to validate the hypothesis that equiaxed microstructure minimizes whisker formation. ${ }^{40}$ It should be noted, however, that mitigation methods must be resistant to reflow conditions.

There are other observations that suggest that an equiaxed microstructure per se may not be the complete story. It is observed that grain boundaries are more mobile with $\mathrm{Pb}$ additions, and in some cases, an equiaxed microstructure can completely transform to a much coarser columnar microstructure within 1 year of electrodeposition. ${ }^{19}$ The strain energy expended in this coarsening necessarily involves stress relaxation in the film, and therefore grain boundary mobility may equally contribute to whisker mitigation in Sn-Pb films. A similar coarsening phenomenon has been observed in Sn-Ag films. ${ }^{51}$ Such a coarsening effect is consistent with observations that matte pure-Sn with coarser grain structure, where wedge-type IMCs at grain boundaries are further apart and hence lower stress generation, is less prone to whiskers than bright $\mathrm{Sn}$ with fine grain structure. Finally, the effect of $\mathrm{Pb}$ may manifest in the form of smaller and more 


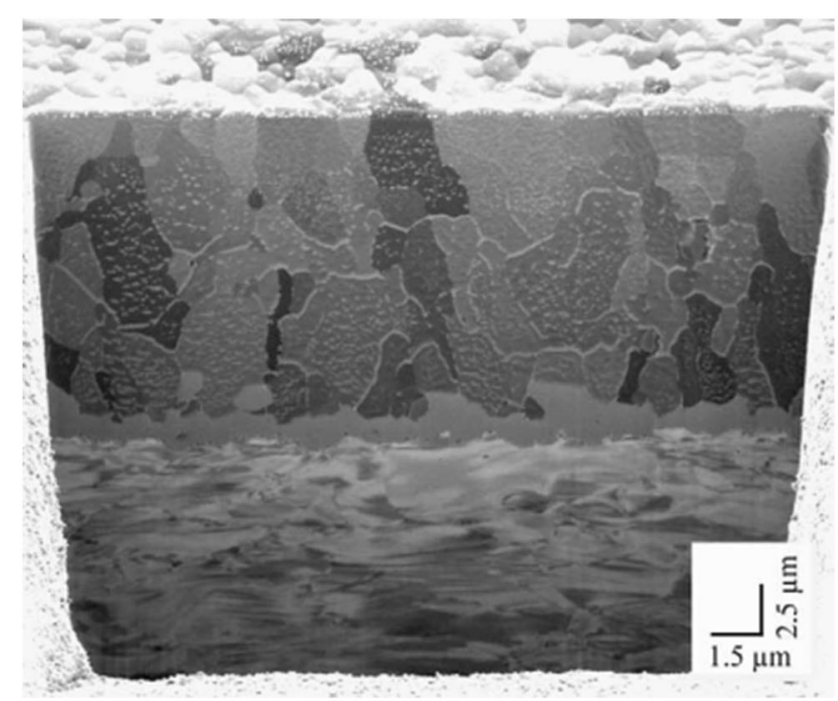

(a)

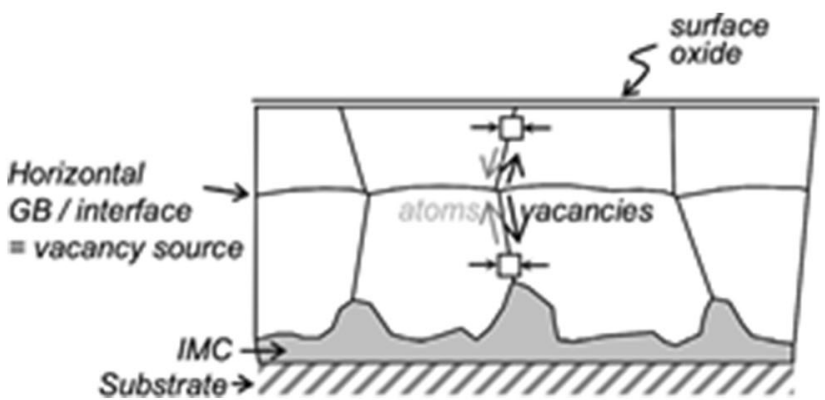

(b)

Fig. 2. (a) Cross-section of $\mathrm{Pb}$-containing $\mathrm{Sn}$ deposit, showing equiaxed microstructure with many horizontal grain boundaries; reprinted with permission from Elsevier. ${ }^{14}$ (b) Schematic showing how horizontal boundaries act as vacancy sources (or atom sinks), thereby absorbing the atom flux flowing up vertical boundaries.

uniformly distributed IMC at the substrate interface, as observed in Refs. 32 and 50. A possible reason may be poisoning of the Sn grain boundary by $\mathrm{Pb}$, forcing IMC formation at all grain boundaries rather than a select few as seems to occur in pure Sn samples. A uniform distribution of IMC would in the limit approximate a planar $\mathrm{Cu}_{6} \mathrm{Sn}_{5}$ front, which would reduce in-plane stress, as discussed above. Note in this context that it may be useful to further investigate the mechanism of uniform IMC formation in various $\mathrm{Pb}$-free alternatives that are being considered, because IMC-generated stress is central to whisker nucleation and growth.

Other studies suggest that whisker mitigation through $\mathrm{Pb}$ may not necessarily depend on the formation of an equiaxed microstructure. Thus, whisker mitigation has been observed in $5-\mu \mathrm{m}$-thick electroplated $\mathrm{Sn}$ with $3 \% \mathrm{~Pb}$, where the FIB-ed cross section revealed a columnar rather than equiaxed microstructure. ${ }^{52}$ Similar mitigation of whiskers was observed in $2-\mu \mathrm{m}$-thick $\mathrm{Sn}-\mathrm{Pb}$ films with columnar microstructure. ${ }^{53}$ Conversely, tin whiskers have been observed in $\mathrm{Sn}-\mathrm{Cu}$ and pure $\mathrm{Sn}$ finishes on lead frames, where FIB cross-sections show equiaxed grain structures. ${ }^{54} \mathrm{Bi}$-doped equiaxed grains of $\mathrm{Sn}^{40}$ do reduce compressive stress, and thereby should minimize whisker growth. We conclude that an equiaxed morphology certainly aids mitigation of Sn whiskers, but other mechanisms also play an important role in tin whisker nucleation and growth.

In recent years, efforts have also been made to understand the role of crystallographic alignment in whisker behavior. Notably, $\beta$-Sn has a body- centered tetragonal structure, where the $c$-axis is much shorter than the $a$-axis $(c=0.318 \mathrm{~nm}$, $a=0.563 \mathrm{~nm}$ ), which results in significant elastic anisotropy. Based on available $C_{i j}$ stiffness parameters, ${ }^{55}$ we calculate $E_{001}=63.9 \mathrm{GPa}$ and $E_{100}=29.7 \mathrm{GPa}$ for $\beta$-Sn. Simultaneously, the thermal expansion coefficient in the $c$-direction is about twice that in the $a$-direction. It follows therefore that a film with a majority of grains with (001) pole (plane normal) aligned with the substrate normal would have lower stress compared with one with (100) or (110) texture. At the same time, if the texture is (110) and there is a minority of grains with (001) poles along the surface normal, then stress can be relaxed by movement of atoms on planes normal to the stress direction in the (110) grains to planes parallel to the substrate in (001) grains, minimizing whisker formation. The effects of anisotropy were recently investigated in Ref. 56 using a multiphysics computational framework in a simulated columnar polycrystalline grain network under strictly thermal stress conditions, highlighting the strong influence of anisotropy and texture on the hydrostatic stress fields that drive diffusion along grain boundaries. Note that the textures typically cited in literature for Sn samples include (112), (321), etc. but not the simple ones mentioned here. Nevertheless, it is relevant to note that Moon et al. $^{25}$ conducted a systematic study correlating deposition parameters to pure Sn film texture. They showed that, beyond an $I_{\text {limit }}$ deposition condition, hydrogen evolution occurred but simultaneously (001) film texture could be realized. However, whisker growth behavior was not reported by those investigators. In separate work, Sarobol et al. ${ }^{57}$ 
observed strong (001) texture in $\mathrm{Sn}-0.2 \mathrm{Cu}-1.3 \mathrm{~Pb}$ film, with multiple of random distribution (MRD) as high as 25. In our own work on codeposited Sn-In alloy, reasonably strong (001) texture with MRD of 4 was obtained. ${ }^{39}$ The latter two studies show hillocks and absence of whiskers, and although other mechanisms are involved, it be may be useful to generate (001) texture through controlled electrodeposition conditions.

\section{LEGACY APPROACHES FOR WHISKER MITIGATION}

To mitigate whiskers, the electronic packaging industry has for years relied on adding $3 \%$ to $50 \%$ lead $(\mathrm{Pb})$ into $\mathrm{Sn}$ films, since it effectively mitigates whiskers. ${ }^{1,3,14} \mathrm{~Pb}$-alloyed samples show primarily hillocks or protrusions, where the aspect ratio (length to diameter ratio) of whiskers is low, typically in the range of 1 to 5 . Note, however, that small whiskers of length less than $40 \mu \mathrm{m}$ have been observed in $\mathrm{Pb}-$ containing Sn electroplating; however, because of their small length, they have not been found to be a major cause for electronic package failure. ${ }^{50}$

Currently, in a more environmentally conscious world, Europe has already imposed a ban on $\mathrm{Pb}$ incorporation through the 2006 European Union Restriction of Hazardous Substances (RoHS) directive. ${ }^{58}$ Importers may only place components that comply with the directive on $\mathrm{Pb}$ onto the $\mathrm{EU}$ market. If products do not follow these guidelines, they may be recalled or removed from the market. Indeed, this is a global issue. Even before the ROHS rule was enacted, the Japanese Ministry for International Trade and the Japanese Automobile Industry Association called for a $50 \%$ reduction of $\mathrm{Pb}$ in automobiles (excluding the battery) by 2001 , and a $66 \%$ reduction by 2003 . Many Japanese manufacturers have moved to a lead-free process in accordance with RoHS guidelines. South Korea also has regulations in place that are in line with the ROHS directive. In 2003, California passed the Electronic Waste Recycling Act of 2003 (EWRA). This law prohibits the sale of electronic devices that are not consistent with the EU RoHS directive after 1 January 2007. In the rest of the USA, even though aerospace and military applications are exempt from $\mathrm{Pb}$-free packaging, many electronic manufacturers are moving away from $\mathrm{Pb}$-containing electronic packaging. The National Electronic Manufacturing Initiative (NEMI) in collaboration with Joint Electronic Device Engineering Council (JEDEC) solid-state technology have proposed standardized testing methods for tin whisker mitigation and risk assessment. ${ }^{59}$

Since the regulatory ban on $\mathrm{Pb}$ in electronics in the mid-2000s, several different methods have been used to mitigate whisker growth, with varied levels of success. One such approach is annealing electroplated samples at $100-150^{\circ} \mathrm{C}$ for $1 \mathrm{~h} \cdot{ }^{10,60}$ One of the possible motivations for this heat treatment is the formation of $\mathrm{Cu}_{3} \mathrm{Sn}$ phase above $60^{\circ} \mathrm{C}$ to $80^{\circ} \mathrm{C},{ }^{22,24,30}$ which may more uniformly spread along the interface and also serve as a stronger barrier to $\mathrm{Cu}$ diffusion. Another method is to include a certain amount of porosity in Sn platings. ${ }^{20}$ Depositing a Ni layer between the $\mathrm{Cu}$ substrate and $\mathrm{Sn}$ has been suggested as an approach to reduce whisker growth because of the low diffusivity of $\mathrm{Cu}$ through the $\mathrm{Ni}$ layer. ${ }^{61,62}$ Low stresses have been observed in Sn films deposited on $\mathrm{Ni}$ substrate, although multiple IMCs form between Sn and Ni. ${ }^{53}$ However, whiskering is only minimized until the $\mathrm{Ni}$ is depleted by its reaction with $\mathrm{Sn}$ and the underlying $\mathrm{Cu}$ to form $(\mathrm{Cu}, \mathrm{Ni})_{6} \mathrm{Sn}_{5}$, thus $\mathrm{Ni}$ underplating is not effective for long-term applications.

A substantial body of work has been reported on the use of conformal coatings on Sn to minimize whisker growth. ${ }^{16-18,63-65}$ Of several polymeric conformal coats examined on assembled electronic packages, Parylene $\mathrm{C}$ coatings have been found to be most effective for suppressing whisker formation. It was further noted that very thin conformal coats were generally unable to contain whisker growth. It has also been suggested ${ }^{66}$ that, when reinforced with 10 wt.\% to 50 wt.\% silica nanoparticles to yield enhanced stiffness and strength, polyurethane coatings are also effective for mitigating whisker formation. In related work, whisker suppression was observed after deposition of tin oxide nanoparticles on electroplated tin. ${ }^{11}$ There is evidence that a weakly adherent conformal coat that delaminates, and therefore bulges out as whiskers grow from the underlying plating, is advantageous for slowing whisker growth, although eventually the whisker may penetrate the coating and grow unabated. A strongly bonded coating, on the other hand, is penetrated early on, and is unable to slow whisker growth. Overall, these mitigation strategies are empirical in nature. They do not address the underlying fundamental issues, such as compressive stress generation and diffusion, that are central to whisker nucleation and growth.

\section{RECENT ADVANCES THROUGH ALLOY DEVELOPMENT}

\section{Effect of Alloy Additions}

In recent work, Nielsen and Woodrow ${ }^{67}$ systematically investigated the roles of a number of binary alloying elements, including $\mathrm{Pb}, \mathrm{Ni}, \mathrm{Co}, \mathrm{Sb}, \mathrm{Au}, \mathrm{Ge}$, and $\mathrm{Cu}$, in whisker growth from Sn. The films were approximately $3 \mu \mathrm{m}$ thick and deposited on pure $\mathrm{Cu}$ substrate. They demonstrated that, while $3.1 \% \mathrm{~Pb}$ slows whisker growth somewhat, the effect is not dramatic. Meanwhile, $1.3 \% \mathrm{Au}, 2.4 \% \mathrm{Sb}$, and $1.1 \%$ Ge were shown to have a larger effect in suppressing whisker formation. An overcoat of $\mathrm{Au}$ on the $\mathrm{Sn}$ coating had an even greater impact on the reduction of Sn whisker formation. It was observed that, in the $\mathrm{Au}$ - and $\mathrm{Ge}$-doped $\mathrm{Sn}$ films, fine precipitates of either an intermetallic or the alloying element were 
formed in the film, along with nanoscale pores. Nanopores were observed in the Sb-doped film as well, although no precipitates were observed. Consistent with previous reports, ${ }^{20}$ this suggests that elemental additives that promote formation of a porous film will mitigate whisker growth. It is notable that the Sn-Ge film exhibited (001) texture along the substrate normal, similar to what has sometimes been observed in $\mathrm{Sn}-\mathrm{Pb}$ films. Therefore, the texture may also have been a factor in the suppression of whiskers in Sn-Ge.

Quite a few studies have been conducted on $\mathrm{Sn}-\mathrm{Bi}$ films because, among other reasons, Bi addition reduces the melting point of the alloy and permits reflow at temperatures lower than those required for pure Sn. It was shown in Ref. 33 that, following 1 year of aging, whiskers were present in both $\mathrm{Bi}$ and Ag-containing Sn films in $2-\mu \mathrm{m}$-thick platings, but that they were essentially absent from $5-\mu \mathrm{m}$ thick coatings. The Sn-Bi samples exhibited a largely columnar microstructure, and from reaction zone observations, the investigators concluded that the reaction zone morphology in the form of finer IMC formation may largely have contributed to the reduced whisker propensity of this alloy film. Pulsed plating of $\mathrm{Sn}-\mathrm{Bi}$ alloys ${ }^{68}$ was conducted in an attempt to form equiaxed morphology in $\mathrm{Pb}$-free tin films. By selective application of pulsed current, the authors successfully formed equiaxed microstructure for alloys with $\mathrm{Bi}$ content down to 3 wt.\%. ${ }^{68}$ However, the whisker resistance of these electroplatings was not reported. In a subsequent publication $^{69}$ using pulsed electroplating, it was reported that whiskers formed in $\mathrm{Sn}, \mathrm{Sn}-\mathrm{Cu}$, and Sn-Zn alloys, but only hillocks were observed in Sn$\mathrm{Bi}$ over a 6-month period. X-ray diffraction (XRD)based stress measurements revealed a stress of - $10 \mathrm{MPa}$ in the Sn-Bi film versus - $29 \mathrm{MPa}$ for the pure $\mathrm{Sn}$ film, suggesting that $\mathrm{Bi}$ was effective in reducing film stress, although the stress reduction mechanism remained unclear. Stress measurements of 7.5- $\mu \mathrm{m}$-thick $\mathrm{Sn}$ and Sn-Bi electroplatings on a Si substrate were conducted in Ref. 70, where stresses were induced by thermally cycling over temperature ranges up to $40^{\circ} \mathrm{C}$. Significant stress relaxation was observed in $\mathrm{Sn}-\mathrm{Bi}$ films compared with pure Sn, irrespective of whether the microstructure was columnar or partially/fully equiaxed, suggesting that mechanisms other than the microstructure contributed to the stress reduction. Whisker growth studies on approximately 5$\mu \mathrm{m}$-thick $\mathrm{Sn}$-Bi electroplatings with Bi content up to 2 wt.\% were conducted in Ref. 71 . They reported no whiskers in $\mathrm{Sn}-2 \mathrm{Bi}$ alloy following 1 year of aging at room temperature. The microstructure showed that the grains were mostly equiaxed in the as-deposited condition, but that changed to columnar morphology after 1 year of aging. This is similar to what has been observed in some $\mathrm{Sn}-\mathrm{Pb}$ alloys mentioned above. The IMC formation in the Sn-Bi case was significantly more uniform and finer than in pure
Sn films, similar to $\mathrm{Sn}-\mathrm{Pb}$ systems, ${ }^{32,50}$ and may have contributed to a lower stress in the $\mathrm{Sn}-2 \mathrm{Bi}$ electroplating. Kim et al. ${ }^{72}$ studied whisker formation in Sn-Bi alloys under thermal cycling conditions. Whiskers were observed in both pure Sn and Sn-10Bi electroplatings, although less so in the Sn10Bi alloy. Cracking was also observed at the surface grain boundaries following thermal cycling, emphasizing the embrittlement effect of $\mathrm{Bi}$ on $\mathrm{Sn}$ electroplatings.

Whisker studies were conducted on Sn-6Ag electroplatings in Ref. 51, with no whiskers being observed over a period of several months. The microstructure revealed a combination of columnar and inclined grain boundaries, along with $\mathrm{Ag}_{3} \mathrm{Sn}$ precipitates at the grain boundaries. Following 4 months of aging at room temperature, the microstructure was coarser and largely columnar, and extensive lateral grain growth was observed. It is suggested that Ag likely contributed to extensive grain growth, and that this growth served to relax stresses when the reaction zone was growing most. This is similar to what was mentioned above for the $\mathrm{Sn}-\mathrm{Pb}$ system $^{19}$ and emphasizes the important role of the stress-induced lateral grain growth contribution to whisker mitigation. In separate work, whisker studies were conducted on $\mathrm{Sn}-\mathrm{Ag}$ films ${ }^{73}$ deposited on thin $\mathrm{Cu}$ film deposited on a $\mathrm{Si}$ substrate. It was found that the whisker density was significantly reduced for the Sn-Ag plating compared with pure Sn, although a quantitative comparison was lacking. $\mathrm{Ag}_{3} \mathrm{Sn}$ was observed at grain boundaries, and the drastic drop in whisker formation was found to be independent of whether the microstructure was equiaxed or columnar. $\mathrm{Zn}$ and $\mathrm{Cu}$ additions have also been utilized in an attempt to mitigate tin whiskers. Zn additions have been found to increase the thickness of the oxide layer, and whiskers with complex morphologies were observed in Ref. 69. On the other hand, the detrimental effect of $\mathrm{Zn}$ on whisker formation and growth has also been reported. ${ }^{48} \mathrm{~A}$ similar detrimental effect of $\mathrm{Cu}$ on whisker formation in $\mathrm{Sn}-\mathrm{Cu}$ electroplating was reported in Ref. 14.

From the discussion above, it is clear that a number of approaches, such as undercoats and overcoats, conformal coating, and alloying with various elements, have been utilized to mitigate whisker growth, with varying degrees of success. Among these, Bi comes close to desired whisker mitigation needs, but suffers from an embrittling effect at higher Bi content. Various arguments have been provided regarding the whisker mitigation mechanisms for Sn-Pb, such as the presence of an equiaxed microstructure, enhanced grain boundary mobility, uniform and finer IMC zone, and reduced grain boundary diffusivity because of $\mathrm{Pb}$ atoms or $\mathrm{Pb}$ islands on the grain boundary. However, the many mechanism studies have failed to provide a path forward to whisker-free Sn electroplating, except the need for a film with reduced in-plane 


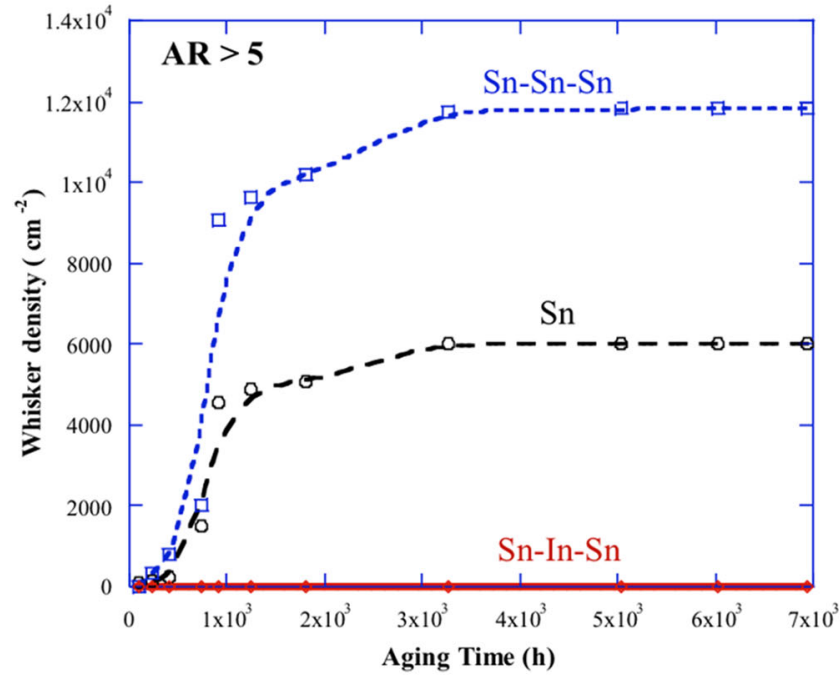

(a)

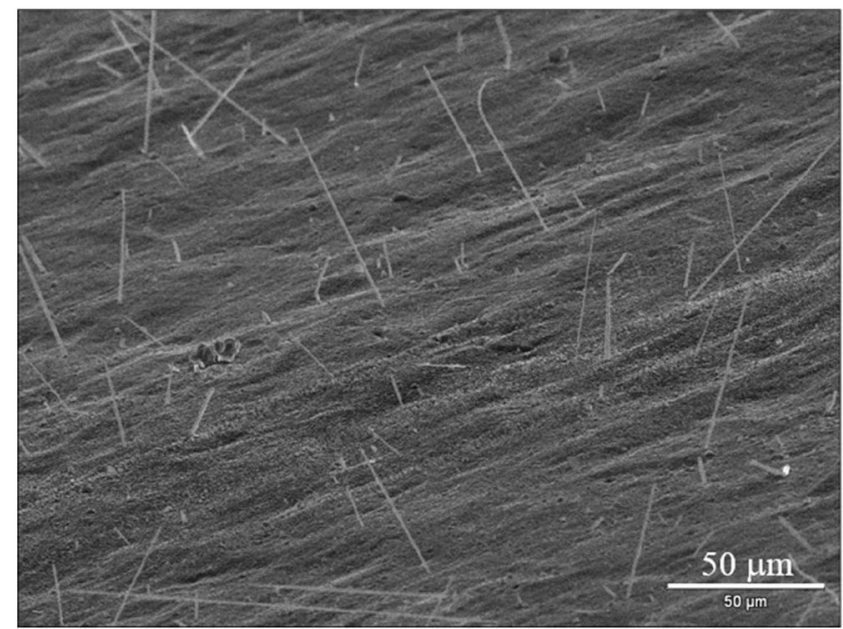

(b)

Fig. 3. (a) Evolution of whisker density (aspect ratio $\geq 5$ ) in $3-\mu \mathrm{m}$-thick films of $\mathrm{Sn}, \mathrm{Sn}$-Sn-Sn, and Sn-In-Sn (10 wt.\% In), with increasing aging time up to 9.6 months at room temperature; reprinted with permission from Springer Publishing. ${ }^{75}$ (b) Profuse whiskering in a $1.6-\mu \mathrm{m}$-thick heattreated $\mathrm{Sn}-\mathrm{Sn}-\mathrm{Sn}$ sample after 1.5 years of aging at RT.

compressive stress. One important missing link has been that none of the previous studies have attempted to manipulate the tenacious $\mathrm{SnO}_{2}$ oxide layer, which is only about $2 \mathrm{~nm}$ thick, but which as mentioned above is a key ingredient that prevents stress relaxation in films of $\mathrm{Sn}$ on $\mathrm{Cu}$, or $\mathrm{Al}$ on $\mathrm{Si}$. Recent work by the current authors has shown that addition of indium significantly influences the oxide layer and effectively stops whisker growth. In the following, results of this work and the mechanistic approaches through which In mitigates whisker growth are presented.

\section{Effect of In Addition}

Recent work has demonstrated that addition of $6 \%$ to $10 \%$ indium prevents growth of long whiskers from electroplated Sn coatings during isothermal aging at room temperature. ${ }^{7-76}$ Unlike with $\mathrm{Pb}$ additions, where whisker growth is mitigated but not eliminated, addition of In at this concentration level completely eliminates whisker growth.

Indium was selected as a dopant primarily because: (a) its atomic number is close to that of Sn (49 for In, 50 for Sn), minimizing the likelihood of chemical interaction; (b) In has moderate solubility in $\mathrm{Sn}$ (around $4 \mathrm{wt. \%}$ at room temperature), which reduces the chance of precipitation of In within the Sn grains, and (c) In forms a strong oxide $\left(\mathrm{In}_{2} \mathrm{O}_{3}\right)$, and moreover with a larger negative free energy of formation compared with $\mathrm{SnO}_{2}$, such that the two oxides could compete for the oxide scale. This would compromise the continuity and tenacity of the oxide layer and permit vacancy flux from the architectured nanoporous oxide surface. Furthermore, $\mathrm{In}^{3+}$ ions in the $\mathrm{Sn}^{4+}$ matrix of the oxide would lead to an anion-deficient oxide, which would also contribute to vacancy formation at the oxide-metal interface. The net result of the vacancy flux would be reduced stress in the electroplating without the need for a whisker-type break at the free surface.

The efficacy of In for mitigation of whisker growth in 1- $\mu \mathrm{m}-, 3-\mu \mathrm{m}$ - and 6- $\mu \mathrm{m}$-thick electroplated Sn was assessed by comparing whisker growth rates in $\mathrm{Sn}$ doped with (6 wt.\% to 10 wt.\%) In versus pure Sn processed under identical conditions. ${ }^{74-76}$ Since an electrolyte was not available initially for codepositing $\mathrm{Sn}$ and $\mathrm{In}, \mathrm{Sn}-\mathrm{In}$ samples on $\mathrm{Cu}$ substrates were made in three layers (i.e., Sn-In-Sn), followed by a diffusion heat treatment to homogenize the through-thickness composition, for comparison with a control trilayer Sn-Sn-Sn sample and a monolithic Sn coating of the same thickness $(1 \mu \mathrm{m}, 3 \mu \mathrm{m}$, or $6 \mu \mathrm{m})$. As seen in Fig. 3a, ${ }^{75}$ no whiskers with aspect ratio $(\mathrm{AR}=$ length/diameter) greater than 5 grew in the $3-\mu \mathrm{m}$ Sn-In-Sn sample, although under the same processing conditions, a high density of whiskers grew in the pure Sn and Sn-Sn-Sn samples. Similar whisker mitigation has been reported for a $1.6-\mu \mathrm{m}$ Sn-In-Sn sample with 7 wt.\% In over a 1.5-year period, where a focused ion beam (FIB) cross section revealed a columnar microstructure. ${ }^{76}$

A major problem with Sn-In codeposition is the significant difference in standard electrode potential with respect to the standard hydrogen electrode between $\mathrm{Sn} / \mathrm{Sn}^{2+}$ and $\mathrm{In} / \mathrm{In}^{3+}$, the difference being much larger compared with $\mathrm{Pb} / \mathrm{Pb}^{2+}$. Nevertheless, electrolytic techniques have now been developed to codeposit Sn-In alloys. ${ }^{77-79}$ By altering the potential conditions in a three-electrode system, the inorganic bath can be used to deposit either pure In or pure $\mathrm{Sn}$, or a range of Sn-In compositions in between. Experiments with these electroplated samples without heat treatment indicate that their performance 


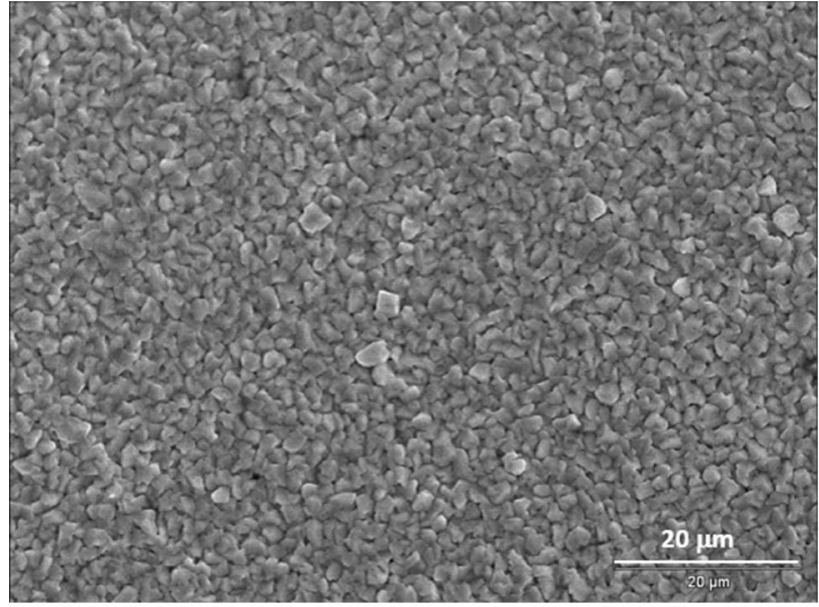

(a)

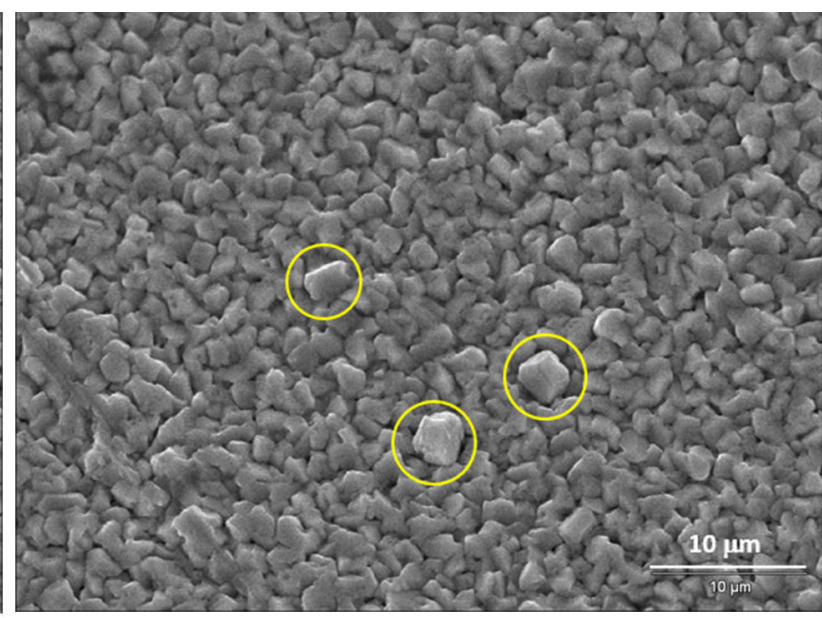

(b)

Fig. 4. SEM images of surface of codeposited Sn-9 wt.\%ln alloy following 1 year of aging at RT: (a) low-magnification image showing overall features and (b) higher-magnification image of protrusions.

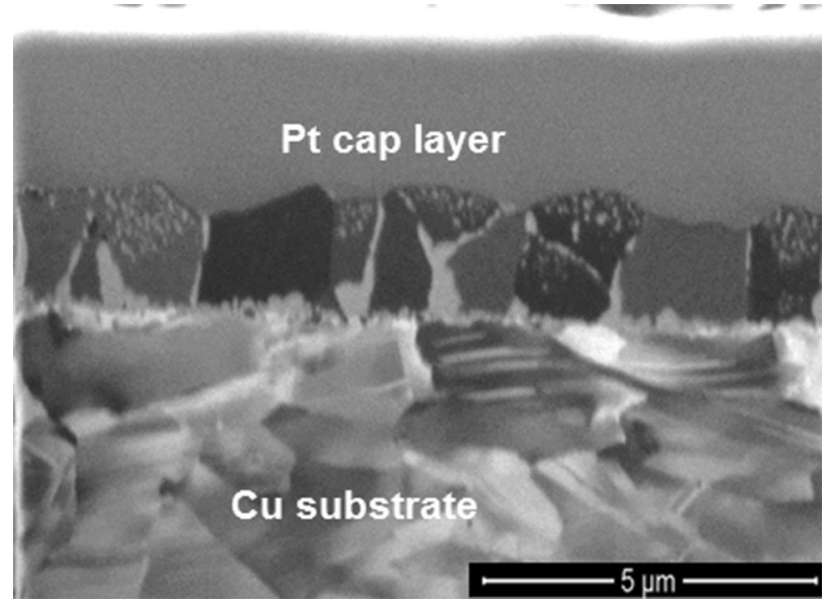

Fig. 5. FIB image of cross section of $1.6-\mu \mathrm{m}$-thick codeposited Sn6ln alloy on Cu substrate.

is similar to the heat-treated multilayered samples discussed above. Thus, Fig. 4 a shows the surface of a codeposited Sn-9In film, which was deposited using an inorganic bath, following 1 year of aging at RT. No protrusions with aspect ratio greater than 5 are observed, and most of them have a stocky structure, as shown in the higher-magnification image in Fig. 4b.

Figure 5 shows a FIB cross section of a codeposited Sn-6In sample approximately $1.5 \mu \mathrm{m}$ thick. At this thickness, the microstructure is largely columnar along with a few oblique grain boundaries. No whiskers have been observed for this composition for almost 2 years now. In thicker films, a combination of columnar and equiaxed grains is observed. ${ }^{75}$

Collaborators at Technic have conducted cyclic thermal shock tests $\left(-55^{\circ} \mathrm{C}\right.$ to $+85^{\circ} \mathrm{C}$, three cycles per hour) as per JEDEC standard JESD20A on coplated Sn-10\%In samples. They found zero whisker growth after 1500 cycles, even though the acceptance standard for this test is whiskers of less than $40 \mu \mathrm{m}$ length, further confirming the efficacy of In for eliminating whisker growth.

In more recent work with indium concentrations less than about $6 \%$ in such codeposited coatings, whiskers of about $25 \mu \mathrm{m}$ length have been observed after approximately 5 months of aging at RT. ${ }^{79}$ However, heat treatment of the film at these lower concentrations demonstrated whisker mitigation. The reasons for a threshold level of indium or the effect of heat treatment remains to be understood.

\section{Role of In in Whisker Growth: Mechanisms}

Based on the whisker growth mechanisms outlined above, the influence of dopants on whisker kinetics may be grouped into the following four categories: (i) change in grain boundary self-diffusivity of Sn, which changes the diffusion of $\mathrm{Sn}$ through the coating (in both lateral and thickness directions) to feed a potential whisker; (ii) change in the compressive stress within the film, which is governed by the reaction kinetics between the substrate and coating; (iii) change in the microstructure to an equiaxed one where vacancies can be created at horizontal grain boundaries or where stress relaxation can occur via highly mobile grain boundaries; and (iv) alteration of the composition and/or morphology of the surface passivation layer (i.e., surface oxide), potentially reducing its stiffness, ${ }^{75}$ strength and tenacity. ${ }^{76}$

The effect of In addition on each of the above mechanisms is briefly presented below:

Influence on Grain Boundary Diffusivity The impact of dopant ( $\mathrm{Pb}$ or $\mathrm{In}$ ) segregation at $\mathrm{Sn}$ grain boundaries was studied by molecular dynamics (MD) simulations, ${ }^{80}$ where a small amount (4 at.\%) of $\mathrm{Pb}$ or In was randomly introduced into 
two lattices straddling a tilt-twist grain boundary. Following equilibration, the solute atoms formed clusters at the grain boundary, similar to the experimental observations of $\mathrm{Pb}$ clustering at $\mathrm{Sn}$ grain boundaries. ${ }^{14}$ Following segregation, the grain boundary self-diffusivity was computed, and the effects of $\mathrm{Pb}$ and In were assessed to be similar. In both cases, the grain boundary self-diffusivity in $\mathrm{Sn}\left(D_{\mathrm{gb}}\right)$ with added dopants was found to be $1 / 3$ to $1 / 2$ of that in pure $\mathrm{Sn}$, indicating that the dopant does reduce the rate of transport of $\mathrm{Sn}$ to the whisker root, but not by enough to rationalize the observed elimination of whisker growth. Therefore, although dopant addition certainly contributes to whisker mitigation by reducing $D_{\mathrm{gb}}$, it appears that this is a relatively minor contributor.

Influence on IMC Morphology As indicated above, $\mathrm{Pb}$ and $\mathrm{Bi}$ appear to form a finer and more homogeneous reaction zone, which in the limit can be approximated as a planar IMC front that would reduce stress development. However, even for these dopants, not much information is available in literature on their effect on stress, apart from the impact of other mechanisms that operate simultaneously. The best one can deduce at present is that they are favorable to whisker mitigation. In the case of Sn-In, significant difficulty was faced during FIB sectioning using Ga ions, because Ga and In form a very low melting eutectic, thus a clear-cut effect of the influence of In on IMC morphology could not be discerned. We note in passing that preliminary glancing-incidence XRD analysis of the IMC layer suggested multiple $\mathrm{Cu}$-In intermetallics $\left(\mathrm{Cu}_{11} \mathrm{In}_{9}\right.$, $\mathrm{Cu}_{7} \mathrm{In}_{3}, \mathrm{Cu}_{4} \mathrm{In}, \mathrm{CuIn}$ ) in addition to $\mathrm{Cu}_{6} \mathrm{Sn}_{5}$. Calculation of the growth kinetics of $\mathrm{Cu}_{11} \mathrm{In}_{9}$ and $\mathrm{Cu}_{6} \mathrm{Sn}_{5}$, based on data from, ${ }^{81}$ showed that $\mathrm{Cu}_{11} \mathrm{In}_{9}$ would likely form first at the $\mathrm{Cu}-\mathrm{Sn}$ interface, followed by formation of $\mathrm{Cu}_{6} \mathrm{Sn}_{5}{ }^{79}$ The diffusivity of $\mathrm{Cu}$ through $\mathrm{Cu}_{11} \mathrm{In}_{9}$ is low compared with $\mathrm{Cu}_{6} \mathrm{Sn}_{5}$, which could impact the IMC volume and thereby stress.

Influence on Microstructure Whisker studies on SnIn alloys have been conducted over a range of plating thicknesses from $1.5 \mu \mathrm{m}$ to $6 \mu \mathrm{m} .{ }^{74-76}$ The microstructure changed from columnar to mixed columnar equiaxed to fully equiaxed morphology as the thickness was increased. Since whiskers were eliminated for all the thicknesses, one may conclude that whisker mitigation due to In did not occur due to the microstructure. However, as mentioned above, an equiaxed microstructure as well as mobile grain boundaries are favorable to whisker mitigation.

Influence on Surface Oxide and Near-Surface Region Angle-resolved x-ray photoelectron spectroscopy (XPS) and Auger electron spectroscopy (AES) have been applied to understand the role of surface and near-surface regions in whisker mitigation. ${ }^{39,76}$ As may be recalled, one of the key requirements for whisker formation and growth is a tenacious oxide film that prevents generation of vacancies in the surface or near-surface region, which could migrate along grain boundaries to mitigate local compressive stresses.

The angle-resolved XPS results indicated that $\mathrm{SnO}_{2}$ in the pure tin sample had a thickness of approximately $2.5 \mathrm{~nm}$, which is consistent with thicknesses reported in literature. For the heattreated Sn-In-Sn multilayered sample, the oxide thickness ranged between $3 \mathrm{~nm}$ and $4 \mathrm{~nm}$ for the heat-treated Sn-In-Sn multilayered sample. Deconvolution of the XPS peak profile for O 1s confirmed that both $\mathrm{SnO}_{2}$ and $\mathrm{In}_{2} \mathrm{O}_{3}$ were present in the oxide layer. ${ }^{39,76}$ In essence, these two oxide species would compete for the same spot in the oxide scale, which could compromise the integrity of the oxide layer. Furthermore, the XPS profile indicated the signatures of $\mathrm{Sn}^{2+}$ and $\mathrm{In}^{2+}$ species, suggesting the formation of a defect structure oxide, namely $\left(\mathrm{Sn}_{1-x} \mathrm{In}_{x}\right) \mathrm{O}_{2-y}$, where $x$ and $y$ represent the stoichiometry of anions and cations, respectively. Note that $\mathrm{SnO}_{2}$ is an $n$-type anionic-deficient oxide with oxygen vacancies, and the addition of $\mathrm{In}^{3+}$ is anticipated to increase oxygen vacancies. These would affect the passivation capability or protectiveness of the oxide, thereby compromising the tenacious natural oxide of Sn. Indeed, cyclic voltammetry studies show that In decreases the passivation properties of the oxide in dilute acidic solution. ${ }^{76}$

The AES depth profile from $^{76}$ is reproduced in Fig. 6a. It shows an enrichment of In in the surface oxide layer and in the subsurface region to a depth of between $20 \mathrm{~nm}$ and $70 \mathrm{~nm}$ below the surface.

After the bulk In composition of approximately 7 wt.\% was reached via sputtering, the sample was exposed to RT air for 2 days and then analyzed again in the Auger instrument. Figure 6a shows that, once again, there was surface enrichment of In following RT exposure, consistent with the rapid diffusion of In along the grain boundaries. The primary driving force for In diffusion to the oxide layer and the subsurface region is believed to be the larger negative free energy of formation for $\operatorname{In}_{2} \mathrm{O}_{3}$ $(-735 \mathrm{~kJ} / \mathrm{mole})$ versus $\mathrm{SnO}(-285 \mathrm{~kJ} / \mathrm{mole})$ or $\mathrm{SnO}_{2}(-527 \mathrm{~kJ} / \mathrm{mole})$. Note that similar surface segregation driven by oxidation reaction has been observed in the past, for $\mathrm{Sn}$ addition to $\mathrm{Pb}$ and $\mathrm{In}$ addition to $\mathrm{Pb}$ systems, ${ }^{82,83}$ so the recently observed segregation of Into the oxide and subsurface region of the Sn-In film is consistent with earlier findings. Surface energy and elastic modulus, $E$, effects may also contribute to the near-surface segregation, where it may be noted that the $E$ values of $\mathrm{Sn}, \mathrm{Pb}$, and In are approximately $42 \mathrm{GPa}, 14 \mathrm{GPa}$, and $12 \mathrm{GPa}$, respectively. Clearly, more work is needed to understand the subsurface segregation.

Further investigations have shown that there is In enrichment at the grain boundaries (Fig. 6b) of the oxide scale, which can be rationalized in terms 


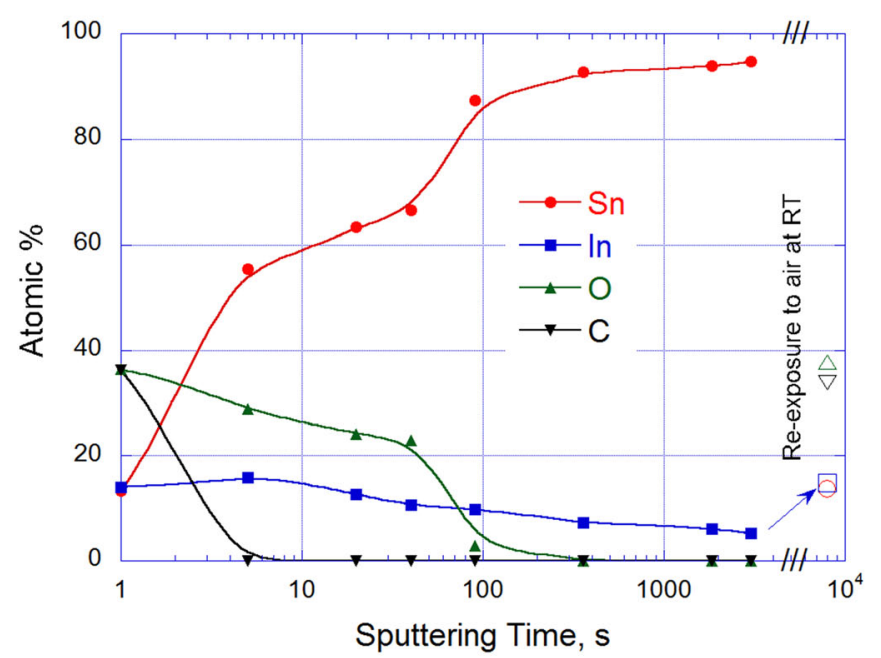

(a)

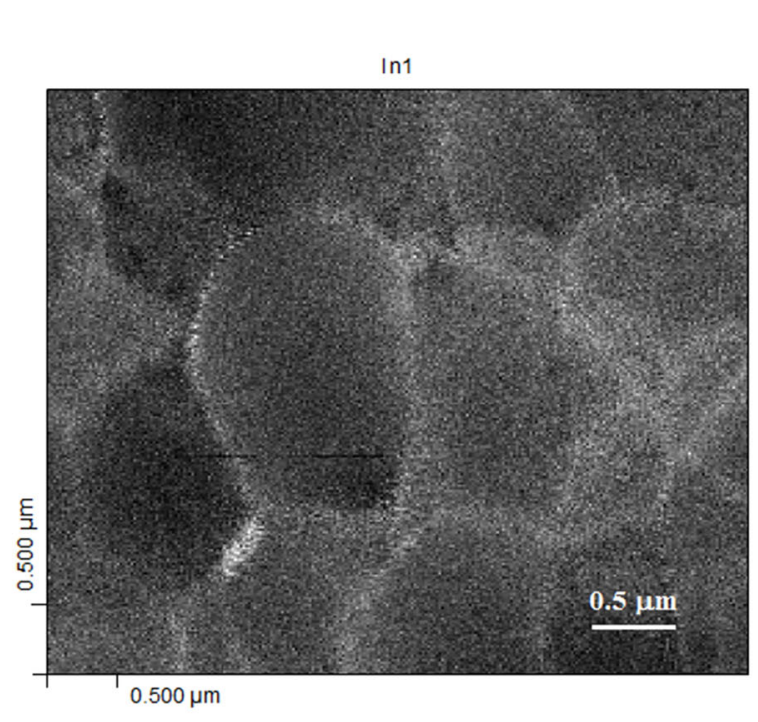

(b)

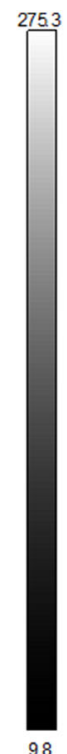

Fig. 6. (a) AES depth profile of $\mathrm{Sn}, \mathrm{In}$, and $\mathrm{O}$ in the $\mathrm{Sn}$-In-Sn sample. The surface and near-surface region shows an enrichment of In compared with the bulk ( $\sim 7$ at. $\%$ In, consistent with EDS analysis). (b) Indium concentration map of the oxide layer of an aged Sn-In-Sn sample with $7 \mathrm{wt} . \%$ In, showing enrichment of In oxide at the grain boundaries. Reprinted with permission from Springer. ${ }^{76}$

of higher grain boundary diffusivity of In compared with bulk diffusivity. This would also imply that defects and possibly cracks in the oxide layer would likely occur at the grain boundaries. However, because of many such boundaries, they can serve as vacancy sources that can release stresses from high compressive stress location regions (Fig. 1b) and thereby relax stresses in the Sn-In film without forming any whiskers, as illustrated in Ref. 76 . Finite element analysis of a Sn-In layer with a porous oxide has shown that the hydrostatic stress gradient is substantially reduced compared with a defect-free oxide layer. ${ }^{84}$ In addition, the In-enriched region below the surface would reduce the local material stiffness and flow strength, and aid stress relaxation of the top region of the electrodeposit where whiskers potentially nucleate.

Surface analytical studies have been conducted for Pb-doped Sn by Wang et al. ${ }^{50}$ and more recently by us. ${ }^{39,76}$ In both of these studies, subsurface segregation of $\mathrm{Pb}$ was observed, ranging from $140 \mathrm{~nm}$ to $250 \mathrm{~nm}$ in depth, and the maximum $\mathrm{Pb}$ enrichment was as much as two to four times the bulk $\mathrm{Pb}$ content (8wt.\% to 14 wt.\%). Barely any $\mathrm{PbO}$ was observed at the surface, suggesting that the surface layer was composed essentially of tin oxide. Depth profiling showed metallic $\mathrm{Pb}$ enrichment just below the oxide layer and in the grain boundary regions, consistent with the phase diagram that shows limited solubility of $\mathrm{Pb}$ in $\mathrm{Sn}$. While the enrichment near the surface can cause surface defects, $\mathrm{Pb}$-enriched grain boundaries can also serve to alter the morphology of the IMC layer at the substrate interface (see the discussion above). Finally, the near-surface enrichment of $\mathrm{Pb}$ and In may be due to multiple causes such as respective surface energies, but more importantly their presence suggests a softer near-surface region that can relax local stresses where whiskers nucleate, thereby preventing whisker nucleation and growth.

\section{CONCLUSION}

Recent progress in tin whisker mitigation strategies is discussed herein. Starting with the three key requirements for whisker nucleation and growth, various strategies are discussed in terms of how they impact whisker mitigation and the mechanisms involved. Most approaches are designed to reduce in-plane compressive stress in the electroplated film, since the stress and more importantly the stress gradient drives the vacancy/atomic flux that is needed for whisker growth.

Literature shows that dopants/alloying elements can alter the IMC formation rate and morphology, which can influence the stress in isothermally aged electroplated films on $\mathrm{Cu}$. The dopant can also alter the morphology of grains from columnar to equiaxed, and can enhance grain boundary migration that can globally alter the film microstructure and locally lead to hillock formation rather than whiskers. While alloying elements have been found to segregate to grain boundaries, their effect on diffusion kinetics is relatively small and cannot explain the strong effect of certain elements in limiting diffusion-mediated whisker growth. Surface analysis and depth profiling using Auger/XPS have demonstrated that dopants can create multiple oxides and defects in the top oxide layer. These competing oxides and defects can compromise the tenacity of the oxide layer and relax stresses, similar to $\mathrm{Fe}$ and $\mathrm{Cu}$, which do not form strongly adhering oxides. In addition to the oxide scale, near- 
surface segregation of dopants can reduce the strength and elastic modulus of the film in the near-surface region and permit stress relaxation in a region where whiskers nucleate. It has been demonstrated that these multiple oxides and subsurface segregation are present for Sn-In electrodeposits, which has been shown by the authors to eliminate whiskers over 1.5 years now. A similar mechanism may also operate for $\mathrm{Sn}-\mathrm{Pb}$ films and help explain why whisker mitigation is observed for this system irrespective of whether the microstructure is equiaxed or columnar.

\section{ACKNOWLEDGEMENTS}

The authors gratefully acknowledge the support of the National Science Foundation (CMMI1335199/1335491) under which this research was conducted as well as the contributions of previous postdoctoral fellows Drs. L. Meinshausen and N. Fredj, as well as undergraduate students L. Soule and A. Buckel who were involved with the Sn-In studies.

\section{REFERENCES}

1. J.A. Brusse, G.J. Ewell, and J.P. Siplon, in CARTS 2002: 22nd Capacitor and Resistor Technology Symposium (New Orleans, 2002), pp. 67-80.

2. H. Leidecker and J.A. Brusse, in Tin Whiskers: A History of Documented Electrical System Failures-A Briefing (Space Shuttle Program Office, 2006), http://nepp.nasa.gov/whiske $r$.

3. G.T. Galyon, The annotated Whisker bibliography and anthology. IEEE Trans. Electron. Packag. Manuf. 28, 94 (2005).

4. J.A. Osenbach, J. Mater. Sci.: Mater. Electron. 18, 283 (2007).

5. J. Cheng, P.T. Vianco, B. Zhang, and J.C.M. Li, Appl. Phys. Lett. 98, 3 (2011).

6. K.S. Kim, J.H. Kim, and S.W. Han, Mater. Lett. 62, 1867 (2008).

7. S.W. Liang, C. Chen, J. Han, L. Xu, K. Tu, and Y. Lai, J. Appl. Phys. 107, 093715 (2010).

8. S.M. Miller, U. Sahayam, and M.G. Norton, Metall. Trans. A 41A, 3386 (2010).

9. U. Sahaym, Mater. Lett. 64, 1547 (2010).

10. M. Sobiech, U. Welzel, R. Schuster, E.J. Mittemeijer, U. Hügel, A. Seekamp, and V. Müller, Appl. Phys. Lett. 93, 011906 (2008).

11. A.T. $\mathrm{Wu}$ and Y.C. Ding, Microelectron. Reliab. 49, 318 (2009).

12. F. Yang, J. Li, J. Ye, and Y. Cheng, J. Power Sources 196, 1474 (2011).

13. K. Zeng and K.N. Tu, Mater. Sci. Eng. R38, 55 (2002).

14. W.J. Boettinger, C.E. Johnson, L.A. Bendersky, K.W. Moon, M.E. Williams, and G.R. Stafford, Acta Mater. 53, 5033 (2005)

15. J. Kadesch, H. Leidecker, and J. Day, Effects of conformal coats on Tin Whisker growth, in NASA Technical Report Proc. IMAP Conference (2000), https://ntrs.nasa.gov/search. jsp?R=20000115612.

16. J. Kadesch and J. Brusse, http://nepp.nasa.gov/eeelinks/Ju ly2001/Articles/JayBrusseRevision2.htm, EEE Links, 1, No. 2 (2001).

17. H. Leidecker and J.S. Kadesch, Effects of Uralane conformal coating on Tin Whisker growth, in Proceedings of the 37th IMAPS Nordic Annual Conference (2000), pp. 108-116.

18. M. Osterman, Tin Whisker Mitigation Latest Findings (2015), https://web.calce.umd.edu/tin-whiskers/presentation s/TinWhiskerMitigations.pdf.
19. M. Sobiech, J. Teufel, U. Welzel, E.J. Mittemeijer, and W. Hugel, J. Electron. Mater. 40, 2300 (2011).

20. J.P. Winterstein and M.G. Norton, J. Mater. Res. 21, 2971 (2006).

21. T.A. Woodrow, Tracer diffusion in whisker prone Sn platings, in Proceedings of SMTA International Conference (2006), pp. 1-50.

22. K.N. Tu, Phys. Rev. B 49, 2030 (1994).

23. K.N. Tu and J.C.M. Li, Mater. Sci. Eng., A 409, 131 (2005).

24. K.N. Tu, C. Chen, and A.T. Wu, J. Mater. Sci.-Mater. Electron. 18, 269 (2007).

25. K.W. Moon, C.E. Johnson, M.E. Williams, O. Kongstein, G.R. Stafford, C.A. Handwerker, and W.J. Boettinger, J. Electron. Mater. 34, L31 (2005).

26. E. Chason, N. Jadhav, W.L.R.L. Chan, and K.S. Kumar, Appl. Phys. Lett. 92, 171901 (2008).

27. E.J. Buchovecky, N.N. Du, and A.F. Bower, Appl. Phys. Lett. 94, 3 (2009).

28. J.W. Shin and E. Chason, J. Mater. Res. 24, 1522 (2009).

29. S.K. Lin, Y. Yorikado, J.X. Jiang, K.S. Kim, K. Suganuma, S.W. Chen, M. Tsujimoto, and I. Yanada, J. Mater. Res. 22, 1975 (2007).

30. K.N. Tu, Acta Mater. 21, 347 (1973).

31. B.Z. Lee and D.N. Lee, Acta Mater. 46, 3701 (1998).

32. W. Zhang and F. Schwager, J. Electrochem. Soc. 153, C337 (2006).

33. A. Baated, K. Hamasaki, S.S. Kim, K.S. Kim, and K. Suganuma, J. Electron. Mater. 40, 2278 (2011).

34. M. Burkhard, S. Kuwano, T. Fujita, I. Dutta, and M.W. Chen, J. Mater. Sci. 45, 3367 (2010).

35. D. Kim, B. Heiland, W.D. Nix, E. Artz, M.D. Deal, and J.D. Plummer, Thin Solid Films 371, 278 (2000).

36. D. Kim, R.P. Vinci, W.D. Nix, M.D. Deal, and J.D. Plummer, J. Appl. Phys. 90, 781 (2001).

37. M. Sobiech, U. Welzel, E.J. Mittemeijer, W. Hugel, and A. Seekamp, Appl. Phys. Lett. 93, 011906 (2008).

38. M. Sobiech, M. Wohlschlogel, U. Welzel, E.J. Mittemeijer, W. Hugel, A. Seekamp, W. Liu, and G.E. Ice, Appl. Phys. Lett. 94, 221901 (2009).

39. S. Bhassyvasantha, Mitigation of Tin Whiskers in electroplated tin coatings by effective doping: the role of the surface and subsurface, in MS Thesis (New Mexico Tech, 2018), p. 84.

40. E. Chason, N. Jadhav, F. Pei, E. Buchovecky, and A. Bower, Prog. Surf. Sci. 88, 103 (2013).

41. N. Jadhav, J. Wasserman, F. Pei, and E. Chason, J. Electron. Mater. 41, 588 (2012).

42. F. Pei, N. Jadhav, and E. Chason, JOM 64, 1176 (2012).

43. P. Sarobol, Y. Wang, W.H. Chen, A.E. Pedigo, J.P. Koppes, J.E. Blendell, and C.A. Handwerker, JOM 65, 1350 (2013).

44. P. Sarobol, J.E. Blendell, and C.A. Handwerker, Acta Mater. 61, 1991 (2013).

45. C.Y. Chang and R.W. Vook, Thin Solid Films 228, 205 (1993).

46. J.W. Shin and E. Chason, Phys. Rev. Lett. 103, 056102 (2009).

47. S.J. Kim, E.A. Stach, and C.A. Handwerker, Thin Solid Films 520, 6189 (2012).

48. M.A. Ashworth, D. Haspel, L. Wu, G.D. Wilcox, and R.J. Mortimer, J. Electron. Mater. 44, 442 (2015).

49. I. Peterson and E. Ahlberg, J. Electroanal. Chem. 485, 166 (2000).

50. J. Wang, M.A. Ashworth, and G.D. Wilcox, IEEE Trans. Compon. Packag. Manuf. Technol. 4, 727 (2014).

51. J. Stein, S. Rehm, U. Welzel, W. Huegel, and E.J. Mittemeijer, J. Electron. Mater. 43, 4308 (2014).

52. J.L. Jo, K.S. Kim, T. Sugahara, S. Nagao, K. Hamasaki, M. Tsujimoto, and K. Suganuma, J. Mater. Sci.-Mater. Electron. 24, 3108 (2013).

53. K. Murakami, M. Okano, M. Hino, M. Takamizawa, and K. Nakai, Mater. Trans. Jpn. Inst. Metals 51, 143 (2010).

54. G.T. Sheng, C.F. Hu, W.J. Choi, K.N. Tu, Y.Y. Bong, and Y. Nguyen, J. Appl. Phys. 92, 64 (2002). 
55. M. Meyers and K. Chawla, Mechanical Behavior of Materials (Cambridge: Cambridge University Press, 2009).

56. A. Chakraborty and P. Eisenlohr, J. Electron. Mater. 48, 85 (2019).

57. P. Sarobol, A.E. Pedigo, P. Su, J.E. Blendell, and C.A. Handwerker, IEEE Trans. Electron. Packag. Manuf. 33, 159 (2010).

58. RoHS, European Union Restiction on Hazardous Substances (ROHS) Directive, in Union OJotE, (Ed.). Off. J.L 037, 19 (2003). Directive 2002/95/EC, vol. Directive 2002/95/ EC, 2002 L37/19-L37/23. European Union (2002).

59. V. Schroeder, IEEE Trans. Electron. Packag. Manuf. 29, 231 (2006). https://doi.org/10.1109/tepm.2006.887397.

60. J.W. Osenbach, J. Appl. Phys. 106, 094903 (2009).

61. H. Gleiter and B. Chalmers, Prog. Mater Sci. 72, 43 (1972).

62. T. Surholt, C. Minkwitz, and C. Herzig, Defect Diffus. Forum 156, 59 (1998).

63. T.A. Woodrow and E.A. Ledbury, in Proceedings of SMTA International Conference (2006).

64. T.A. Woodrow and E.A. Ledbury, in IPC-JEDEC 8th International Conference on Lead-Free Electronic Components and Assemblies (2005), pp. 1-25.

65. S. Han, M. Osterman, S. Meschter, and M. Pecht, J. Electron. Mater. 41, 2508 (2012).

66. S. Maganty, M.P.C. Roma, S.J. Meschter, D. Starkey, M. Gomez, D.G. Edwards, A. Ekin, K. Elsken, and J.Y. Cho, Prog. Org. Coat. 90, 243 (2016).

67. J.A. Nielsen and T.A. Woodrow, The role of trace elements in tin whisker growth, in Final Project Report for SERDP Project WP-1751, Strategic Environmental Research and Development Program (SERDP) (2013), 286 p.

68. E. Sandnes, M.E. Williams, M.D. Vaudin, and G.R. Stafford, J. Electron. Mater. 37, 490 (2008).

69. A. Dimitrovska and R. Kovacevic, J. Electron. Mater. 38, 2726 (2009)

70. N. Jadhav, M. Williams, F. Pei, G. Stafford, and E. Chason, J. Electron. Mater. 42, 312 (2013).
71. J.L. Jo, S. Nagao, K. Hamasaki, M. Tsujimoto, T. Sugahara, and K. Suganuma, J. Electron. Mater. 43, 1 (2014).

72. K.S. Kim, C.H. Yu, and J.M. Yang, Microelectron. Reliab. 46, 1080 (2006).

73. J. Chang, S.K. Kang, J.H. Lee, K.S. Kim, and H.M. Lee, J. Electron. Mater. 43, 259 (2014)

74. L. Meinshausen, S. Bhassyvasantha, B.S. Majumdar, and I. Dutta, J. Electron. Mater. 45, 791 (2016).

75. S.D. Mahapatra, B.S. Majumdar, I. Dutta, and S. Bhassyvasantha, J. Electron. Mater. 46, 4062 (2017).

76. S. Bhassyvasantha, N. Fredj, S.D. Mahapatra, W. Jennings, I. Dutta, and B.S. Majumdar, J. Electron. Mater. 47, 6229 (2018).

77. B.S. Majumdar, S. Bhassyvasantha, and L. Soule, Tin-indium alloy electroplating solution, US patent application no. 16/220,683 \& PCT/US18/65759 (2018).

78. I. Dutta and S.D. Mahapatra, Method of electroplating tin films with indium using an alkanesulfonic acid based electrolyte, US patent application pub. no. US2017/0321340 (2017).

79. S.D. Mahapatra and I. Dutta, Surf. Coat. Technol. 337, 478 (2018).

80. S. Banerjee, I. Dutta, and B.S. Majumdar, Mater. Sci. Eng., A 666, 191 (2016).

81. D.G. Kim, Mater. Trans. 44, 72 (2003).

82. N.J. Chou, S.K. Lahiri, R. Hammer, and K.L. Komarek, J. Chem. Phys. 63, 2758 (1975).

83. R.A. Konetzki and Y.A. Chang, J. Mater. Res. 3, 466 (1988).

84. S.D. Mahapatra and I. Dutta, Mater. Sci. Eng. A 706, 181 (2017).

Publisher's Note Springer Nature remains neutral with regard to jurisdictional claims in published maps and institutional affiliations. 